\title{
Initial Outcomes with Customized Myopic LASIK, Guided by Automated Ray Tracing Optimization: A Novel Technique
}

This article was published in the following Dove Press journal: Clinical Ophthalmology

\section{Anastasios John \\ Kanellopoulos ${ }^{1,2}$ \\ 'Laservision.gr Clinical and Research Institute, Athens, Greece; ${ }^{2}$ NYU Medical School, Department of Ophthalmology, New York City, NY, USA}

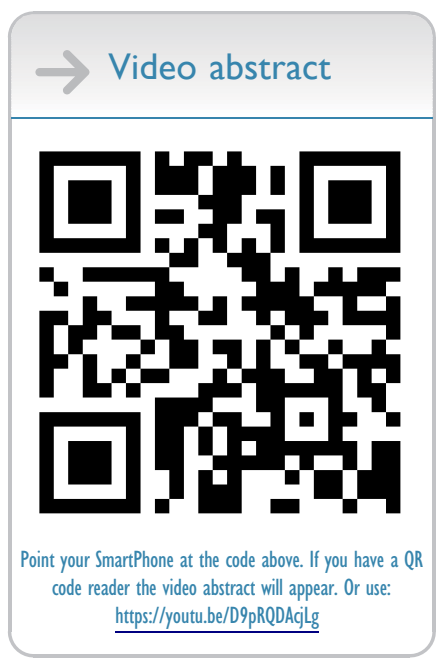

Correspondence: Anastasios John Kanellopoulos

Laservision.gr Clinical and Research

Institute, 17 Tsocha Street, Athens II5

21, Greece

Tel +302107472777

Fax + 302107472789

Email ajkmd@mac.com
Purpose: Safety and efficacy of a novel automated ray tracing optimization in customization of excimer ablation in myopic LASIK.

Methods: In a consecutive case series, 25 patients (50 eyes) undergoing femtosecond-laserassisted myopic LASIK were evaluated. The novel, artificial-intelligence platform initially calculates the ablation profile based on a model eye for each case, based on interferometry axial length data. Low- and high-order aberration calculation is performed by raytracing based on wavefront and Scheimpflug tomography measurements, all from a single diagnostic device. Visual acuity, refractive error, keratometry, topography, high-order aberrations and contrast sensitivity were evaluated, over six months follow-up.

Results: Change from pre- to 6 months post-operative: mean refractive error improved from $-5.06 \pm 2.54$ diopters $(\mathrm{D})$ (range -8.0 to $-0.50 \mathrm{D}$ ) to $-0.11 \pm 0.09 \mathrm{D}$ (range -0.25 to +0.25 ); refractive astigmatism from $-1.07 \pm 0.91 \mathrm{D}$ (range -4.25 to $0 \mathrm{D}$ ) to $-0.15 \pm 0.04 \mathrm{D}$ (range -0.25 to 0 ); and topographic astigmatism from $-1.65 \pm 0.85 \mathrm{D}$ to $-0.26 \pm 0.11 \mathrm{D}$ (range -0.60 to 0 ). About $65 \%$ of eyes gained one line of vision and 38\% 2 lines. Pre- to post-operative high-order aberration average: RMSh changed from 0.25 um to $0.35 \mathrm{um}$. Contrast sensitivity improved postoperatively.

Conclusion: We report safe and effective preliminary outcomes with a novel excimer laser customization by ray tracing optimization, for myopic LASIK treatments, employing several independent up-till-now diagnostics and a customized eye model reference for each case. It bears the potential advantage through total eye aberration data and ray tracing refraction calculation to offer improved and more predictable visual outcomes.

Keywords: ray tracing excimer customization, topography-guided, wavefront-guided, femtosecond-laser assisted myopic LASIK, customized excimer ablation

\section{Introduction}

Laser-assisted in situ keratomileusis (LASIK) has become one of the most effective and safe methods for correcting refractive error with laser corneal intervention, ${ }^{1,2}$ as evidenced by the long and large number of publications in the peer-reviewed literature.

In recent years, bladeless LASIK surgery utilizing a femtosecond laser (owing the name to the ultra short pulses, with duration of few femto-sec, that is $10-15$ of a sec) as an alternative option for lamellar flap creation to the mechanical microkeratome has been used extensive clinically with improved outcomes. $1,3,4$,

The second laser involved in the LASIK procedure, the excimer, executes the ablation, and has also evolved significantly over the course of the past twenty years. 
Most contemporary generation excimer lasers for refractive surgery operate with high pulse repetition (more than $400 \mathrm{~Hz}),{ }^{5,6}$ flying spot, ${ }^{7,8}$ and can provide customized ablation, including aspheric ablation profiles, wavefrontguided, or topography-guided treatments. ${ }^{9-12}$

These improvements have further advanced the clinical outcomes of the LASIK procedure, in attempting to not just correct the spherocylindrical refractive error, but also of the higher-order aberrations by reducing induced spherical and other aberrations within the myopic ablations. ${ }^{13-15}$

The purpose of this study was to evaluate the safety, efficacy and stability in myopic and myopic astigmatism LASIK procedures utilizing the Alcon-WaveLight FS200 femtosecond and EX500 excimer laser refractive surgery platform guided by a novel ray tracing-optimization software utilizing Wavefront, Scheimpflug tomography and axial length measurement data from a single diagnostic device.

\section{Methods}

This study received approval by the Ethics Committee of our Institution: The Laservision ambulatory eye center Ethics Committee and adhered to the tenets of the Declaration of Helsinki. Written informed consent was obtained at the time of the first study visit. All equipment, techniques and materials had been already approved for clinical use within the EU (CE mark); thus, neither the technique nor the technology was experimental.

\section{Patient Enrollment Inclusion Criteria}

Subjects between the ages of 18-65 years of age undergoing LASIK. Pre-operative myopia of up to $-9 \mathrm{D}$ and up to $-6 \mathrm{D}$ of astigmatism. Pre-operative minimum corneal thickness, as defined by Scheimpflug corneal tomography measurement, of at least $500 \mu \mathrm{m}$.

\section{Exclusion Criteria}

Previous ocular surgery, clinically significant corneal abnormalities including scar in the visual axis, anterior basement membrane dystrophy, clinical signs of dry eye and/or blepharitis, to include significant superficial punctuate keratitis and/or significant epithelial irregularity in the anterior segment OCT epithelial mapping. Keratoconus (even suspect as defined by Scheimpflug corneal tomography analysis application of the Amsler-Krumeich criteria). Last cornea surface irregularity beyond ectasia detection, as defined by Placido-disc corneal topography (regularity and qualitative distribution of astigmatic "bowtie").
All eyes were evaluated pre- and post-operatively for UDVA and CDVA with the manifest clinical refraction. Pre- and post-operative evaluations included wavefront, Scheimpflug anterior segment tomography, and axial length interferometry analysis by the single novel device: Sitemap (Alcon, Ft. Worth, TX), anterior segment OCT $9 \mathrm{~mm}$ corneal thickness and epithelial thickness mapping (Avanti, Optovue, CA) and contrast sensitivity utilizing the functional vision analyzer (Stereo Optical, Chicago, IL, USA). Post-operative examination included UDVA, and manifest and dilated refraction and CDVA measurement, slit-lamp microscopy, IOP measurement and wide field fundoscopy (Optomap, California, Optos Inc., Marlborough, MA)

\section{Ray Tracing Technique (Innoveyes)}

The Sitemap ${ }^{\circledR}$ device and the artificial intelligence processing are in essence an adapted Pentacam ${ }^{\circledR}$ AXL Wave device (Oculus, Germany) as the diagnostic data arm of artificial intelligence platform that provides customized profiles to the EX500 excimer platform. The software introduces a new laser-spot surface distribution and sequence: The Innoveyesguided ablation carries redesigned spot delivery when compared to the original Wavefront-optimized profile introduced by WaveLight in its excimer-laser series (adapted in 2000, treating $20-30 \%$ more spots in the periphery of the ablation in order to account for essential energy loss due to the longer spot travel and its oblique delivery and thus improve ablation zone and reduce asphericity), and aims to correct some of the shortcomings with the original profile patterns.

The laser during the Innoveyes treatment treats simultaneously sphere, cylinder, and high-order aberrations, and its calculation of the treatment takes into consideration the expected post-op epithelial remodeling and the expected biomechanical changes of each myopic and myopic-astigmatic treatment (obviously relevant to the amount of sphere and tissue removed) thus preemptively calculating the appropriate "nomogram" adjustments to the final ablation profile.

The data collection methodology key points are:

A - 4 Wavefront map captures are needed, through an at least $5.5 \mathrm{~mm}$ in mesopic pupil diameter at the moment of capture. The processed measurement readout then offers 2 sets of data: one at pupillary-aperture-simulation of $4 \mathrm{~mm}$ and one of $6.5 \mathrm{~mm}$.

B - 4 reproducible Scheimpflug tomography images are also required: quality-threshold flagged by the device, but the user has to manually exclude measurements to improve consistency of those chosen to proceed (very similar to previous topography-guided (TCAT) software 
for Placido-disc imaging (Vario, Topolyzer, Alcon, Ft. Worth, TX)), Scheimpflug (Oculyzer II, Alcon, Ft. Worth, TX). Scheimpflug-suggested cylinder is the total cylinder of the cornea (anterior and posterior cornea consideration) at the corneal vertex.

C - 4-6 axial length measurements required and captured by the Sitemap device.

The sequence of suggested measurements is to start from the Wavefront capture in both eyes first, to then continue with the Scheimpflug and axial length measurements in one eye to be followed by the other. This was recommended to reduce the chance of pupillary miosis due to accommodation by the patient during the measurement process.

Figure 1 illustrates some of the sitemap readouts on a specific case:

1A shows an overview of wavefront refraction @ 4mm pupillary zone on the top and wavefront map on the left and tomography map on the right, $1 \mathrm{~B}$ the axial length interferometry measurements used in the calculations, $1 \mathrm{C}$ illustrates a comparative overview of the tomography maps and 1D those of the wavefront.

Other differences from predecessor software: treatment platform posts on top the clinical refraction, then the Innoveyes-calculated treatment, but the default treatment presented by the software on the bottom of list is the actual
Innoveyes-proposed refraction treatment, not the manifest clinical refraction (as in older customized versions used on the same excimer laser: Topography-guided with trade name Contoura, wavefront-guided with trade name ACAT, and Q value adjusted with trade name FCAT).

The novel treatment described herein can be manually adjusted by the surgical team for: sphere, cylinder and/or axis, but this adjustment cannot exclude Wavefront and/or Topographic data, and/or tilt. When Wavefront data are not available, the ray tracing calculation cannot proceed, so the Innoveyes treatment data cannot become available. The same stands for the other 2 measurement types: Tomography and axial length measurements.

The actual Innoveyes ray tracing treatment is calculated from the diagnostic data noted above and captured with the single diagnostic device: the Sitemap data are transferred by the Sitemap device through a proprietary Ethernet network that facilitates export and data transfer to the treatment calculation computer of the excimer laser. Once received by the treatment computer the data are processed by the artificial intelligence in the device software in 4 steps to calculate ray tracing in 2 "opposite" directions: Step 1: The axial length measurements give precise measurements of all anatomical refractive surfaces in the line-of-sight and a theoretical model eye is "constructed" with them, in order
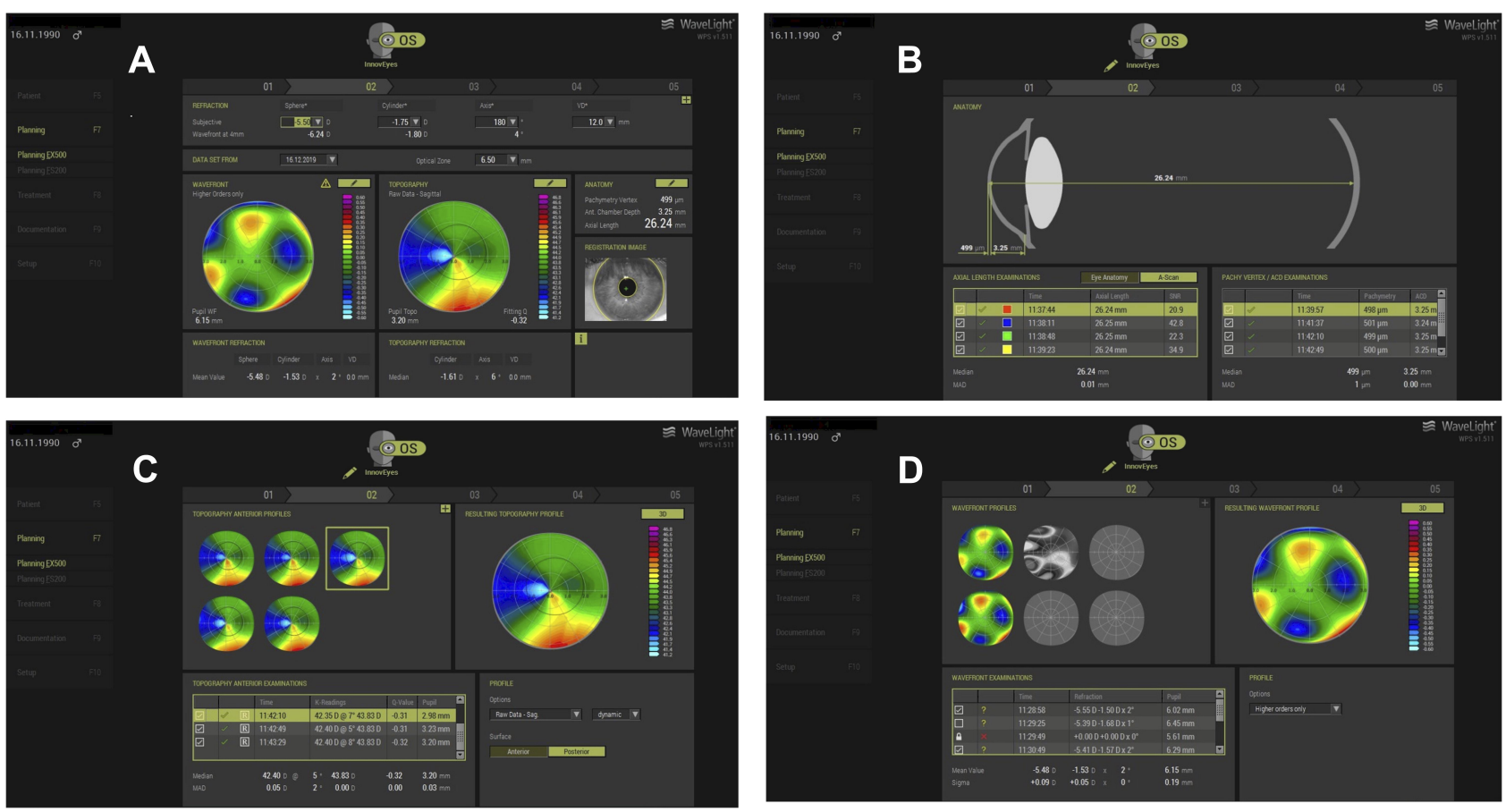

Figure I This image illustrates some of the sitemap readouts on a specific case: (A) shows an overview of wavefront refraction @ $4 \mathrm{~mm}$ pupillary zone on the top and wavefront map on the left and tomography map on the right, (B) the axial length interferometry measurements that are actually used as an initial step in order to create the customized "model" eye for the ray tracing calculations that follow, (C) illustrates a comparative overview of the tomography maps and (D) those of the wavefront. 
to proceed to the next steps. Step 2: The corneal tomography measurements are used to calculate the propagation of light rays (2000 in number) through the anterior corneal surface, the cornea stroma, out the posterior corneal surface, through the anterior chamber and onto the anterior lens surface.

Step 3: The Wavefront data are used to calculate each of the above light-ray "travel" in a retrograde fashion: From the retina, through the vitreous cavity, onto the posterior lens surface, through the crystalline lens, and onto the anterior surface of the lens. 2000 rays are actually traced and calculated in these 2 steps for the algorithm determination.

Step 4: A final fourth step: Tilt is calculated by the Scheimpflug tomography images and the incidence of rays projected onto the anterior surface of the cornea. The internal tilt between the actual anterior cornea surface orientation towards the ray tracing orientation used in steps 2 and 3 is additionally taken into consideration and corrected by the Innoveyes artificial intelligence software. The software attempts to "line-up" the corneal surface to the whole eye orientation used in the ray tracing steps 2 and 3, thus adjusts the cornea surface by applying a prism-like ablation in order to perform the high-order aberration correction measured on the optimally conformed anterior corneal surface. We used the Innoveyes software suggested refraction for treatment in all cases instead of the actual subjective clinical refraction. The software overview of the suggested treatment following the noted ray tracing calculations in the case described in Figure 1, is illustrated in Figure 2.

At the completion of each LASIK treatment, a bandage contact lens $(+0.50$ D, BC: 9.2 and $14 \mathrm{~mm}$ diameter, Acuvue, Johnson-Johnson) was placed on the cornea until the following morning when it was removed, along with one drop of Moxifloxacin drops (Vigamox, Alcon Ft. Worth, TX) and one drop of a combination 1\% dexamethasone and $0.3 \%$ chloramphenicol (Dispesadron-C, Alcon).

The postoperative regimen was continued 4 times a day for 1 week.

Follow-up visits were 1 day, 1 week, month 1 , month 2 , month 3 , and month 6 .

Visual acuity, refractive error measured again by the sitemap device captures and calculations and crossreferenced with the dry manifest subjective refraction, keratometry, Scheimpflug tomography, Wavefront analysis of high-order aberrations, contrast sensitivity and repeat final postoperative refraction and aberrations-calculation by the Sitemap device were evaluated, over six months follow-up.

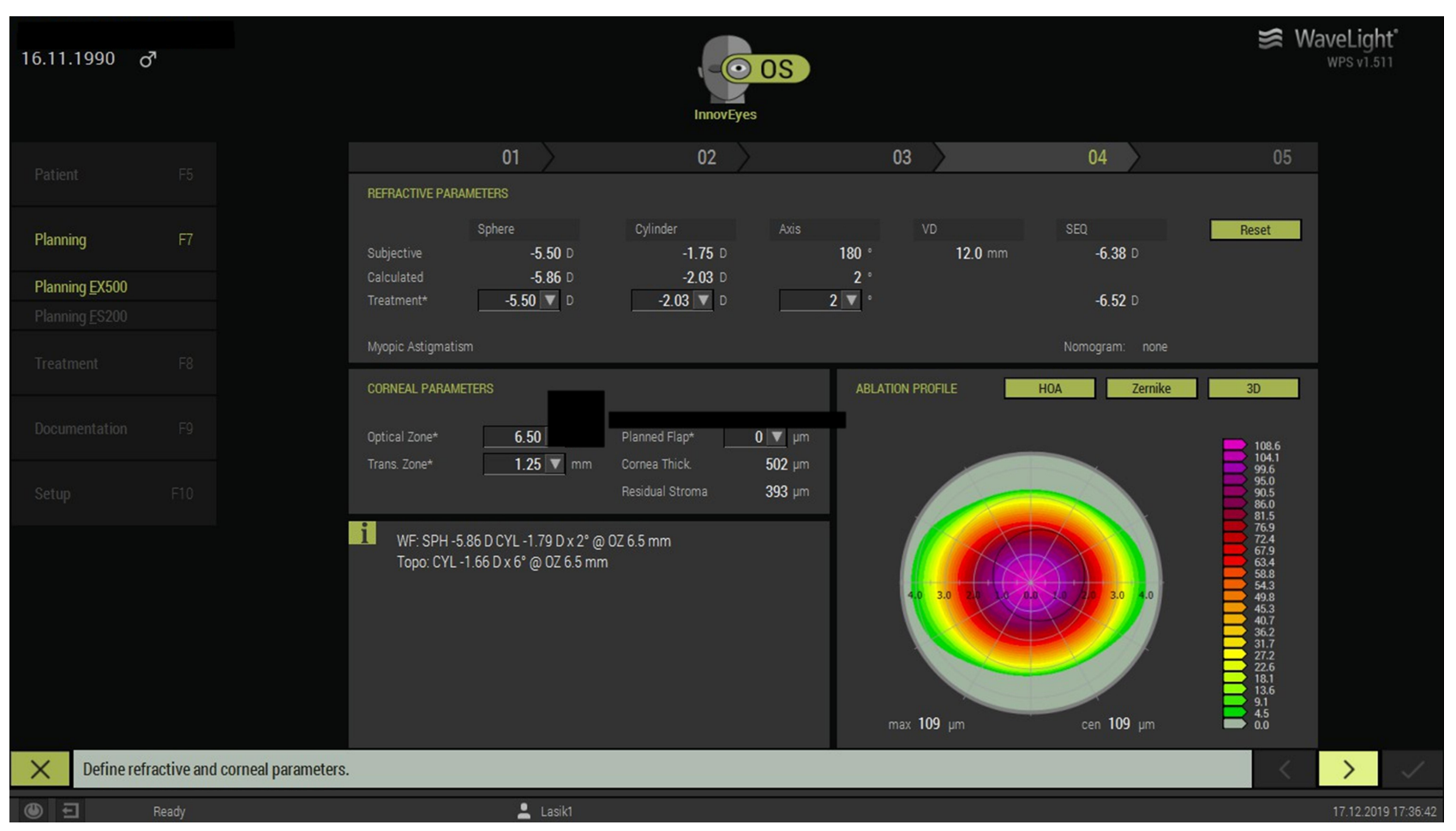

Figure 2 Customized treatment profile employed in the Innoveyes treatment for the same eye noted in. Figure I, as illustrated by the EX500 excimer laser treatment Innoveyes software. The software overview of the suggested treatment following the noted ray tracing calculations in the case described in Figure I. 


\section{Results}

Of the 25 patients (mean age 36 (19 to 48)) enrolled 5 were unable to be treated with this technology for the following reasons: 1 patient ( 2 eyes) was not spontaneously reaching pupillary aperture to a minimum of $5.5 \mathrm{~mm}$ necessary for the device wavefront capture. Two other patients (4 eyes) fulfilled all diagnostic criteria, but were calculated to have more than 10 degrees tilt correction (11 to 17), and were as such excluded by our team from proceeding with the Innoveyes treatment. Last: 2 patients ( 4 eyes) were excluded, as their epithelial maps and the Placido-derived topography revealed significant anterior corneal surface irregularity and thus were excluded by our team from the treatment and further evaluation in this study.

Of the 20 patients (40 eyes) that completed the Innoveyes customized femtosecond-laser assisted LASIK procedure we collected the following data:

Change from pre- to post-operative values at 3 months: mean refractive error improved from $-5.06 \pm 2.54$ diopters (D) (range -8.0 to $-0.50 \mathrm{D}$ ) to $-0.11 \pm 0.09 \mathrm{D}$ (range -0.25 to +0.25 ); Refractive astigmatism from $-1.07 \pm 0.91 \mathrm{D}$ (range -4.25 to $0 \mathrm{D}$ ) to $-0.15 \pm 0.04 \mathrm{D}$ (range -0.25 to 0 ), topographic astigmatism from $-1.65 \pm 0.85 \mathrm{D}$ to $-0.26 \pm 0.11$ $\mathrm{D}$ (range -0.60 to 0 ). $65 \%$ of eyes gained one line of vision and 38\% 2 lines. Cumulative refractive data are illustrated in Figure 3. Pre-to post-operative total high-order aberrations measured by the RMSh metric (total high-order aberrations), changed from 0.25 um to $0.35 \mathrm{um}$. Contrast sensitivity measured pre-operatively appears improved when measured postoperatively as an average, as demonstrated in Figure 4.

\section{Discussion}

The manifest clinical refraction has been utilized up until now as a globally accepted gold-standard in laser vision correction applied to the cornea, either as LASIK, PRK and even Smile. ${ }^{16}$

It has been through the study of topography-guided excimer treatments and especially in highly irregular eyes, that often the clinical refraction astigmatism amount, and axis, can be very different when compared to the topographic measured astigmatism. We have reported that the subjective manifest measurements present usually less cylindrical power and even different axis when compared to the topographic corneal data. Our clinical experience in treating irregular corneas with topography-guided excimer ablations has been previously reported in the literature and over 1000 cases have been carefully analyzed and evaluated for this principle. ${ }^{11,12,17}$ Our early experience had guided us to work in those irregular eyes, more with the topography-guided suggested data, modifying accordingly the subjective manifest refraction data.

Topography-guided treatments in routine otherwise healthy myopic cases were studied carefully in a FDA study submitted by ALCON and established improved visual outcomes compared to previously submitted treatment platforms. ${ }^{18}$ In that study $19.57 \%$ of cases evaluated reached at 12 months, UDVA at least 1 line better than the pre-operative CDVA, and $8.26 \%$, of the cases, 2 lines better, likely through the reduction of low- and highorder corneal aberrations treated by-default when topography-guided treatments are employed in virgin eyes.

We combined this previous experience in studying topography-based modification of the up-until-now "gold" standard manifest clinical refraction used in LASIK treatments. We thus introduced the principle of Topography-Modified Refraction (TMR) in a randomized contralateral-eye study. ${ }^{19}$ We reported that TMR used in a contralateral-eye study may offer even better outcomes than those documented in topography-guided treatments earlier.

There has been earlier work reported in attempting to optimize the excimer laser ablation with manual calculation of theoretical ray tracing based on wavefront, topography and axial length measurement data combined. ${ }^{20-22}$

The ray tracing concept described for over 10 years in these studies, as a means of refractive outcome optimization, using manual calculations from wavefront, corneal topography and interferometry axial length measurements.

We describe here the first clinical data with ray tracing optimization of the refraction to be treated along with the high-order aberrations, processed by artificial intelligence and with the multiple measurements performed from one novel single diagnostic device, used for the first time in customized LASIK for myopic eyes.

The ability to include total eye refractive and aberration data in the customization appears to overcome several unknowns when compared to our previous long experience of 15 years in "manually" calculating and optimizing the excimer ablation in these eyes with anterior corneal curvature data-alone, or wavefront data alone, and surgeon "forecasting" the expected refractive changes that will take place, as we did with TMR. Potential imitations of this technology already encountered in this small study may include the ability to potentially image some of these eyes through more irregular corneas, or eyes that cannot offer the capture standards set for the combination diagnostic device (Sitemap) such as the minimum pupillary mesopic diameter of $5.5 \mathrm{~mm}$. As studied herein, 


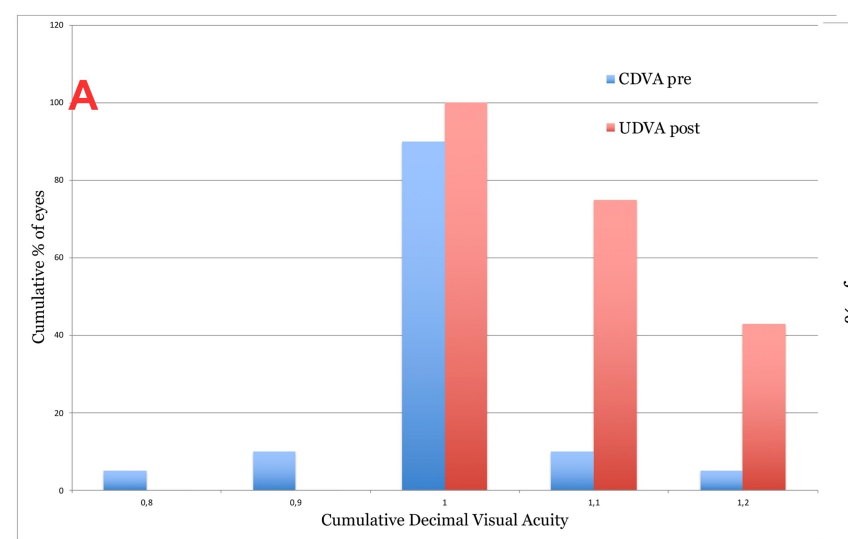

Uncorrected Distance Visual Acuity

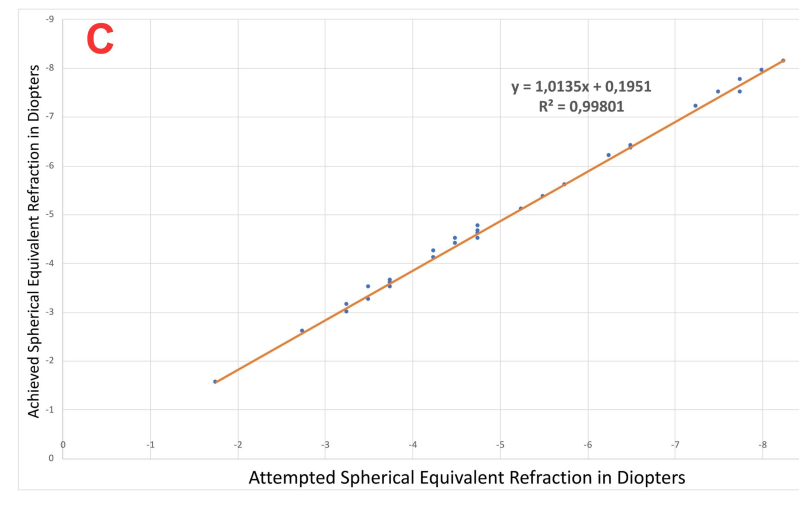

Spherical Equivalent Attempted vs. Achieved

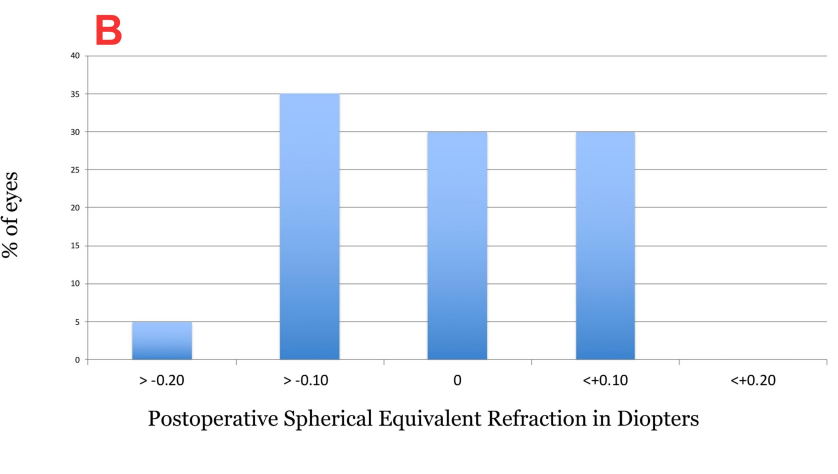

Change in Corrected Distance Visual Acuity

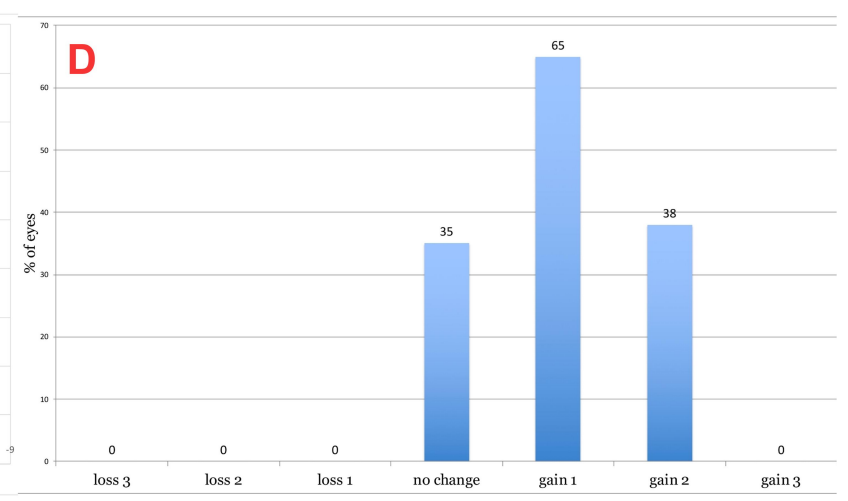

Spherical Equivalent Refractive Accuracy

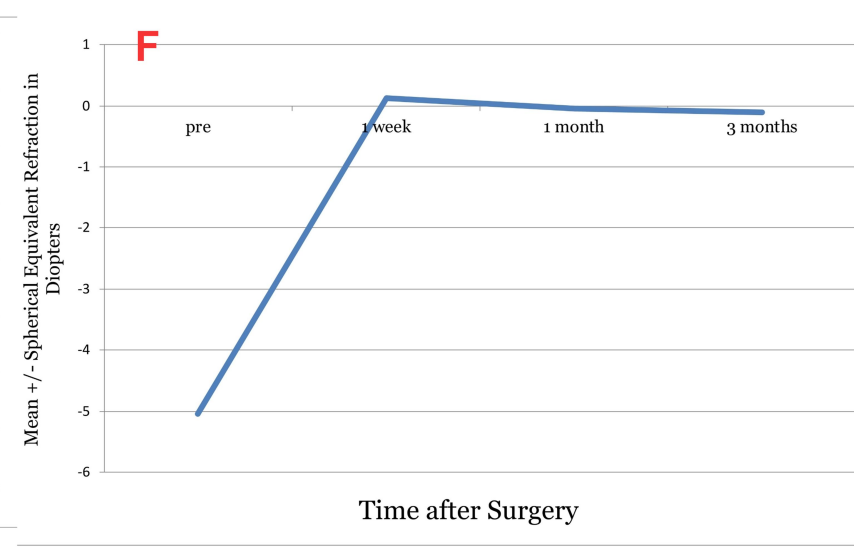

Refractive Astigmatism
Stability of Spherical Equivalent Refraction

Figure 3 Cumulative outcome data in graphs: UDVA=uncorrected distance visual acuity, CDVA=corrected distance visual acuity, SE=spherical equivalent. Top left image $(\mathbf{A})$ demonstrates the pre-operative CDVA plotted with the postoperative UDVA, the top right image (B) demonstrates the change in CDVA pre- to post-op, the middle left image (C) demonstrates the attempted vs achieved spherical equivalent refractive error scatter and $r^{2}$ relationship between them. The middle right image (D) demonstrates the postoperative spherical equivalent refraction in Diopters. The bottom left image $(\mathbf{E})$ demonstrates the change in refractive astigmatism values in diopters from pre $=$ op to post-op, and last the bottom right image $(\mathbf{F})$ demonstrates the stability of spherical equivalent refraction from pre- to I week, I month and 6 month intervals. 


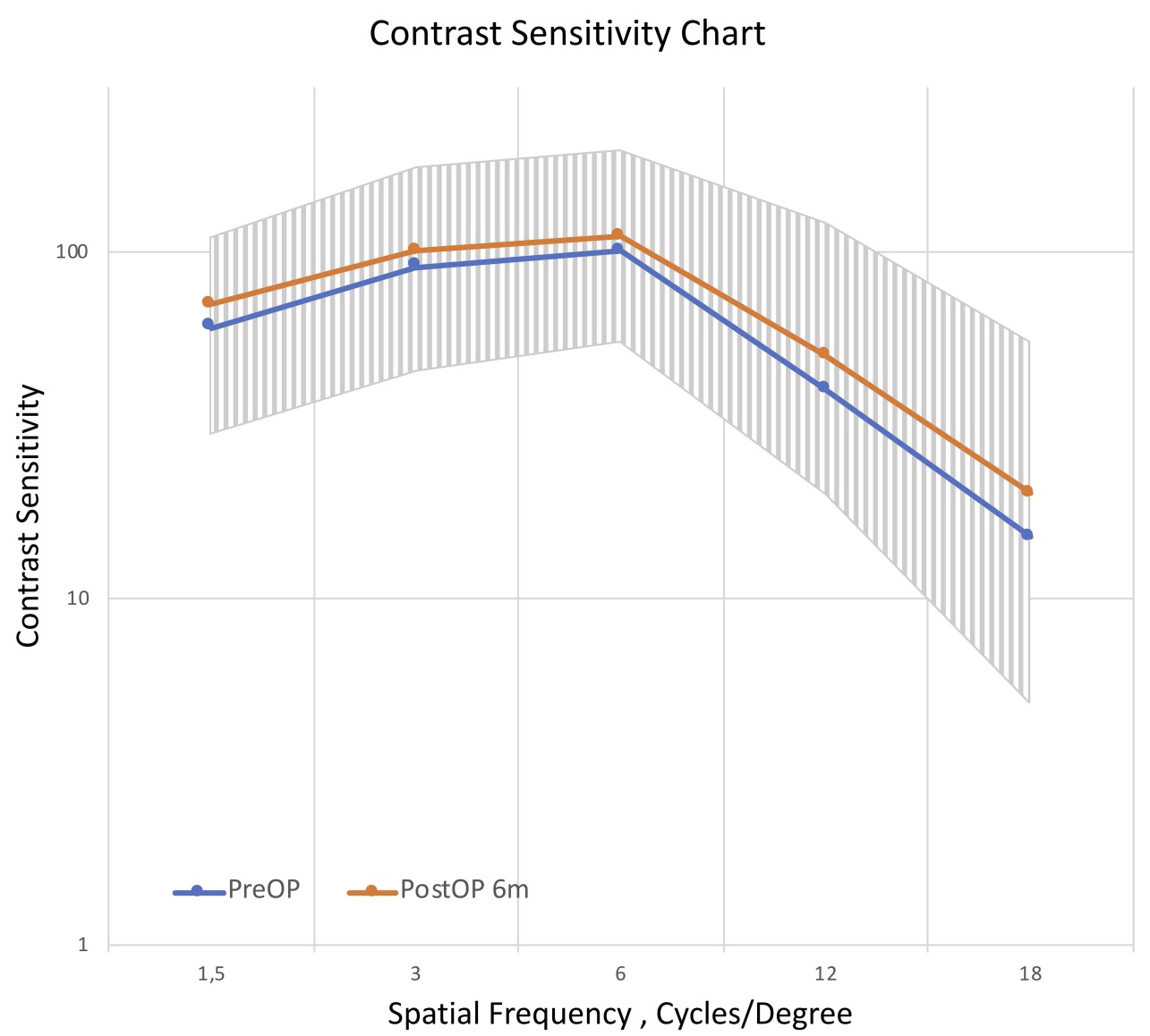

Figure 4 This image illustrates the contrast sensitivity measured in several cycles/degree points preoperative and at 6 months postoperative. It appears improved when measured postoperatively as an average in all cycles/degree points measured.

this technology can offer as an advantage the ability to selfevaluate its accuracy of measurement and ablation precisiondelivery, through the post-operative measurements of residual refractive error and aberrations.

The majority of current refractive excimer laser treatments, are all based on manifest refraction or can be customized using a single customization with either wavefront, topography or even-in a simpler fashion-asphericity data. All these customized treatments use the Gullstrand standard eye model to make calculations based on several refractive average values of the eye.

The novelty of the level of customization with the Innoveyes customized ray tracing platform used in the study presented herein, lays in the fact that it customizes each refractive treatment, based on actual individual eye measurements, provided by the Sitemap diagnostic device, instead of the standard Gullstrand-eye model values used up till know. ${ }^{23}$ The ray tracing calculation is performed through a theoretical eye model that is "constructed" by the objective interferometry axial length data, for each eye measured.
Finally, we used anterior segment OCT pre-operative mapping of the corneal epithelium at $9 \mathrm{~mm}$ diameter, and Placido-disc topography, as our own confirmation of the "naivety" of the anterior corneal surface, and a means of validating the reliability of the sitemap measurements-that assume as a prerequisite pristine optics. In the case of significant corneal epithelial irregularity being noted, the case was excluded from imaging and treating with the sitemap data and this study. We thus excluded a significant percentage of candidate eyes based on this protocol. We support the practice of careful screening of the candidate cases by epithelial mapping and Placido-disc topography-both means of establishing anterior corneal surface regularity-as an important screening step. ${ }^{23-29}$

Further studies may further validate the data presented in this preliminary feasibility study.

\section{Conclusions}

We herein introduce preliminary data with a novel diagnostic technology and surgical technique, utilizing ray tracing calculation by artificial intelligence that combines wavefront, 
Scheimpflug tomography and interferometry axial length measurements that appear to indeed customize safe and effective in regard to visual outcomes, myopic LASIK treatments.

\section{Acknowledgment}

This work was presented in part as a poster at the winter ESCRS meeting in Marrakesh, Morocco, February, 2020.

\section{Funding}

There is no funding to report.

\section{Disclosure}

The author reports no conflicts of interest for this work.

\section{References}

1. Wen D, McAlinden C, Flitcroft I, et al. Postoperative efficacy, predictability, safety, and visual quality of laser corneal refractive surgery: a network meta-analysis. Am J Ophthalmol. 2017;178:65-78. doi:10.1016/j.ajo.2017.03.013

2. Lukenda A, Martinović ZK, Kalauz M. Excimer laser correction of hyperopia, hyperopic and mixed astigmatism: past, present, and future. Acta Clin Croat. 2012;51(2):299-304.

3. Reggiani-Mello G, Krueger RR. Comparison of commercially available femtosecond lasers in refractive surgery. Exp Rev Ophthalmol. 2011;6(1):55-56. doi:10.1586/eop.10.80

4. Salomão $\mathrm{MQ}$, Wilson SE. Femtosecond laser in laser in situ keratomileusis. J Cataract Refract Surg. 2010;36(6):1024-1032. doi:10.1016/j.jcrs.2010.03.025

5. Vega-Estrada A, Alió JL, Arba Mosquera S, Moreno LJ. Corneal higher order aberrations after LASIK for high myopia with a fast repetition rate excimer laser, optimized ablation profile, and femtosecond laser-assisted flap. J Refract Surg. 2012;28(10):689-696. doi:10.3928/1081597X-20120921-03

6. Winkler von Mohrenfels C, Khoramnia R, Lohmann C-P. Comparison of different excimer laser ablation frequencies $(50$, 200, and $500 \mathrm{~Hz}$ ). Graefes Arch Clin Exp Ophthalmol. 2009;247 (11):1539-1545. doi:10.1007/s00417-009-1102-x

7. Iseli HP, Mrochen M, Hafezi F, Seiler T. Clinical photoablation with a $500-\mathrm{Hz}$ scanning spot excimer laser. $J$ Refract Surg. 2004;20 (6):831-834. doi:10.3928/1081-597X-20041101-12

8. de Ortueta D, Magnago T, Triefenbach N, Arba Mosquera S, Sauer U, Brunsmann U. In vivo measurements of thermal load during ablation in high-speed laser corneal refractive surgery. J Refract Surg. 2012;28(1):53-58. doi:10.3928/1081597X-20110906-01

9. Kanellopoulos AJ, Pe LH. Wavefront-guided enhancements using the wavelight excimer laser in symptomatic eyes previously treated with LASIK. $J$ Refract Sur. 2006;22(4):345-349. doi:10.3928/1081-597X20060401-08

10. Smadja D, Reggiani-Mello G, Santhiago MR, Krueger RR. Wavefront ablation profiles in refractive surgery: description, results, and limitations. J Refract Surg. 2012;28(3):224-232. doi:10.3928/ 1081597X-20120217-01

11. Kanellopoulos AJ. Topography-guided custom retreatments in 27 symptomatic eyes. J Refract Surg. 2005;21(5):S513-8. doi:10.3928/ 1081-597X-20050901-19

12. Kanellopoulos AJ. Topography-guided hyperopic and hyperopic astigmatism femtosecond laser-assisted LASIK: long-term experience with the $400 \mathrm{~Hz}$ eye-Q excimer platform.Clin Ophthalmol. 2012;6:895-901. doi:10.2147/OPTH.S23573
13. Zheng H, Song LW. Visual quality of Q-value-guided LASIK in the treatment of high myopia. Yan Ke Xue Bao. 2011;26(4):208-210.

14. Alio JL, Vega-Estrada A, Piñero DP. Laser-assisted in situ keratomileusis in high levels of myopia with the amaris excimer laser using optimized aspherical profiles. Am $J$ Ophthalmol. 2011;152 (6):954-963.

15. El Awady HE, Ghanem AA, Saleh SM. Wavefront-optimized ablation versus topography-guided customized ablation in myopic LASIK: comparative study of higher order aberrations. Ophthalmic Surg Lasers Imaging. 2011;42(4):314-320. doi:10.3928/15428877-20110421-01

16. Kanellopoulos AJ, Kanellopoulos AJ. Reporting acuity outcomes and refractive accuracy after LASIK. $J$ Refract Surg. 2014;30 (12):798-799. doi:10.3928/1081597X-20141113-01

17. Kanellopoulos AJ, Asimellis A. Comparison of Placido disc and Scheimpflug image-derived topography-guided excimer laser surface normalization combined with higher fluence CXL: the Athens Protocol, in progressive keratoconus. Clin Ophthalmol. 2013;7:1385-1396. doi:10.2147/OPTH.S44745

18. WaveLight ALLEGRETTO WAVE ${ }^{\circledR}$ Eye-Q Excimer Laser P020050/S012, Summary of Safety and Effectiveness Data, page 31; 2020. https://www.accessdata.fda.gov/cdrh_docs/pdf2/ P020050S012b.pdf. Assessed March 1, 2020.

19. Kanellopoulos AJ. Topography-modified refraction (TMR): adjustment of treated cylinder amount and axis to the topography versus standard clinical refraction in myopic topography-guided LASIK.Clin Ophthalmol. 2016;10(10):2213-2221. doi:10.2147/OPTH.S122345

20. Mrochen M, Bueeler M, Donitzky C, et al. Optical ray tracing for the calculation of optimized corneal ablation profiles in refractive surgery planning. J Refract Surg. 2008;24:S446-S451.

21. Schumacher S, Seiler T, Cummings A, Maus M, Mrochen M. Optical ray tracing-guided laser in situ keratomileusis for moderate to high myopic astigmatism. J Cataract Refractive Surg. 2012;38(1):28-34. doi:10.1016/j.jcrs.2011.06.032

22. Cummings AB, Kelly K. Optical ray tracing-guided myopic laser in situ keratomileusis: 1-year clinical outcomes. Clin Ophthalmol. 2013;7:1181-1191. doi:10.2147/OPTH.S44720

23. Gobbi PG, Carones F, Brancato R. Keratometric index, videokeratography, and refractive surgery. J Cataract Refract Surg. 1998;24 (2):202-211. doi:10.1016/S0886-3350(98)80201-0

24. Kanellopoulos AJ, Asimellis G. In vivo three-dimensional corneal epithelium imaging in normal eyes by anterior-segment optical coherence tomography: a clinical reference study. Cornea. 2013;32 (11):1493-1498. doi:10.1097/ICO.0b013e3182a15cee

25. Kanellopoulos AJ, Asimellis G. In vivo 3-dimensional corneal epithelial thickness mapping as an indicator of dry eye: preliminary clinical assessment. Am J Ophthalmol. 2014;157(1):63-68. doi:10.1016/j.ajo.2013.08.025

26. Kanellopoulos AJ, Aslanides IM, Asimellis A. Correlation between epithelial thickness in normal corneas, untreated ectatic corneas, and ectatic corneas previously treated with CXL; is overall epithelial thickness a very early ectasia prognostic factor? Clin Ophthalmol. 2012;6:789-800. doi:10.2147/OPTH.S31524

27. Hwang ES, Schallhorn JM, Randleman JB. Utility of regional epithelial thickness measurements in corneal evaluations. Surv Ophthalmol. 2020;65(2):187-204. doi:10.1016/j.survophthal.2019.09.003

28. Salomão MQ, Hofling-Lima AL, Lopes BT, et al. Role of the corneal epithelium measurements in keratorefractive surgery. Curr Opinion Ophthalmol. 2017;28(4):326-336. doi:10.1097/ICU.0000000000 000379

29. Reinstein DZ, Archer TJ, Gobbe M. Refractive and topographic errors in topography-guided ablation produced by epithelial compensation predicted by 3D Artemis VHF digital ultrasound stromal and epithelial thickness mapping. J Refract Surg. 2012;28(9):657-663. doi:10.3928/1081597X-20120815-02 


\section{Publish your work in this journal}

Clinical Ophthalmology is an international, peer-reviewed journal covering all subspecialties within ophthalmology. Key topics include: Optometry; Visual science; Pharmacology and drug therapy in eye diseases; Basic Sciences; Primary and Secondary eye care; Patient Safety and Quality of Care Improvements. This journal is indexed on PubMed
Central and CAS, and is the official journal of The Society of Clinical Ophthalmology (SCO). The manuscript management system is completely online and includes a very quick and fair peer-review system, which is all easy to use. Visit http://www.dovepress.com/ testimonials.php to read real quotes from published authors.

Submit your manuscript here: https://www.dovepress.com/clinical-ophthalmology-journal 